PHYSICAL ACTIVITY, LONELINESS \& SOCIAL ISOLATION

Ilona I. McMullan, (1), Brendan P. Bunting, Annette Burns (2), Lee Smith (3), Connor Cunningham (2), Roger O'Sullivan (2), Nicole E. Blackburn (1), Jason J. Wilson (1), Mark A. Tully (1)

1 Institute of Mental Health Sciences, School of Health Sciences, Ulster University, Newtownabbey, United Kingdom. Email: i.mcmullan@ulster.ac.uk; m.tully@ulster.ac.uk, bp.bunting@ulster.ac.uk; ne.blackburn@ulster.ac.uk; ii.wilson@ulster.ac.uk

2. Institute of Public Health in Ireland, Belfast/Dublin. Email: conor.cunningham@publichealth.ie; annette.burns@publichealth.ie; roger.osullivan@publichealth.ie

3. Cambridge Centre for Sport and Exercise Sciences, Anglia Ruskin University, Compass House, Cambridge, CB1 1PT. Lee.smith@anglian.ac.uk

\section{Is Physical Activity Associated With Loneliness or Social Isolation In Older Adults? Results of a longitudinal analysis using the TILDA Study.}


PHYSICAL ACTIVITY, LONELINESS \& SOCIAL ISOLATION

21

22

23

24

25

26

27

28

29

30 
PHYSICAL ACTIVITY, LONELINESS \& SOCIAL ISOLATION

\section{Abstract}

32 Social relationships are central to the health and well-being of older adults. Evidence exploring the

33 association of physical activity (PA) with social isolation and loneliness is limited. This study uses a

34 path analysis to investigate the longitudinal association between loneliness and social isolation with

PA using the Irish Longitudinal study of Ageing (TILDA). Higher levels of social isolation measured using the Berkman-Syme Social Network Index (SNI) were directly and indirectly associated with lower levels of walking, moderate PA (MPA) and vigorous PA (VPA) over six years. Additionally, higher levels of walking were associated with lower levels of loneliness measured using a modified version of the University of California Los Angeles loneliness scale (UCLA) over a 3-year period. of different types of PA on loneliness over time.

Key words 
PHYSICAL ACTIVITY, LONELINESS \& SOCIAL ISOLATION

\section{Introduction}

Loneliness is a subjective experience which describes the lack of meaningful connections and relationships. It is the subjective difference between an individual's preferred and actual situation, where as social isolation is an objective measurement of the number of relations, social interactions, social support structures, engagements and activities (Fried et al., 2020; Shvedko et al., 2018; Steptoe et al., 2013; Weis, 1975). Importantly, both concepts are related, but the two do not always correlate and individuals may feel lonely despite having many social contacts, while others may not experience loneliness despite having few social contacts (McHugh et al., 2017; Perlman \& Peplau, 1981). Furthermore, many factors such as individual characteristics, cultural factors, and the social environment can influence both loneliness and social isolation (Schrempft et al., 2019; Shvedko et al., 2018).

Loneliness and social isolation are not an inevitable part of growing older, and data from the UK over the last number of decades indicates that chronic loneliness is present in just $8-9 \%$ of older adults (65+) (Victor et al. 2002) while 34\% of those aged 52 and over in England reported they are 'sometimes'(25\%) or 'often'(9\%) lonely in $2009-2010$ based on data from the English Longitudinal Study on Ageing (Beaumont, 2013). Older adults may be more at risk of loneliness or social isolation due to increased difficulty in maintaining social participation following a decrease in mobility or health, increased poverty, as well as a loss of social resources through bereavement (Aartsen \& Jylhä, 2011;.Bukov et al., 2002; Desrosiers et al., 2004; Glass et al., 2006; Griffin, 2010; Levasseur et al., 2011; Maier \& Klumb, 2005; Nicholson, 2012; Victor, 2011). Loneliness in older adults is particularly concerning due to the wide range of associated negative health consequences (Pels \& Kleinert, 2016). Research suggests that either through psychobiological or behavioural pathways, loneliness increases the risk of chronic disease (Lauder et al., 2006; Senez et al., 2004; Shankar et al., 2011; Thurston \& Kubzanskv, 2009); cognitive impairment (Pitkala et al., 2011); and all-cause mortality (Elovanio et al., 2017; Patterson \& Veensta, 2010; Newall et al., 2013). A more recent umbrella review of observational studies (795 studies, and 746,706 participants) suggests an association between loneliness and 
PHYSICAL ACTIVITY, LONELINESS \& SOCIAL ISOLATION dementia (relative risk, $\mathrm{RR}=1.26$; $95 \% \mathrm{Cl}$ : 1.14-1.40, 12 23.6\%), paranoia (odds ratio, $\mathrm{OR}=3.36 ; 95 \% \mathrm{Cl}$ : 2.51-4.49, 12 92.8\%) and psychotic symptoms (OR=2.33; 95\%Cl: 1.68-3.22, 12 56.5\%) (Solmi et al., 2020). It is estimated that the social and healthcare benefits of addressing loneliness in the UK are approximately $£ 900$ per person per annum (Bernard, 2013). Consequently, there is a need to understand how this growing public health concern might be addressed.

The health benefits of physical activity (PA) in older adults are well established (Bangsbo et al., 2019; Cunningham et al., 2020; Silverman \& Duester, 2014; Fried et al; 2020), and loneliness reduction models suggest that PA may also have an important role for loneliness through social, psychological, and biological mechanisms (Shvedko et al., 2018). For example, Social Compensation Effect theory suggests that PA increases social participation through group activities which can compensate for the loss of meaningful social relationships, provide opportunities to develop relationships, and facilitate an individual's perception of social support (Ferraro \& Farmer, 1995, Sheridan et al., 2014); the Broaden and Build Theory of Positive Emotions theory suggests that PA generates positive emotions and feelings of well-being which removes the barriers to social interaction and consequently reduces Ioneliness (Cohen \& Wills, 1985; Fredrickson, 1998; Milligan et al., 2013; Newhall et. al., 2013); and the Tripartite Model of Group Identification suggests that through cognitive, affective, and behaviour a sense of identification and social attraction to group members with shared interests and goals can develop during PA which decreases loneliness (Hawkley et al., 2009; Henry et al., 1999).

Whilst emerging, studies exploring the association between PA and loneliness in older adults are limited. More specifically, Shvedko et al.'s (2018) systematic review (n= 38 studies; 5288 participants) suggests that there is a lack of evidence regarding the effectiveness of PA interventions with only one study ( $n=294$ participants; mean age=23.6 years) supporting the efficacy of the tripartite model successfully decreasing loneliness in the context of PA interventions. Additionally, studies exploring the longitudinal association between PA and loneliness are lacking (Fried et al., 2020; Tully et al., 2019; Victor \& Bowling, 2011). For example, Pels et al.'s (2016) systematic review ( $n=37$ studies) exploring 
PHYSICAL ACTIVITY, LONELINESS \& SOCIAL ISOLATION

\section{Method}

\section{Participants}

119 TILDA is an ongoing cohort study of ageing that includes community-dwelling older adults ( $\geq 50$ years)

the association between PA and loneliness found that PA can contribute to a decrease in loneliness and that loneliness itself might reduce the probability of being physically active. However, most studies included were cross-sectional (24 studies), with only seven longitudinal studies of which only three explored the effect of PA on loneliness. Also, previous studies have highlighted the dynamic nature of loneliness experienced by older adults, and so establishing the factors linked to loneliness within a life course or longitudinal perspective is important to better inform the design of more effective interventions in a rapidly ageing society (Solmi et al., 2020; Victor et al., 2009).

This study aims to bring new insights to the understanding of the association between PA and loneliness in older adults using secondary data analysis of longitudinal data from the Irish Longitudinal study of Ageing (TILDA). The questions addressed were: (1) what changes occur in PA, loneliness, and social isolation over time in older adults? and (2) what is the relationship between PA, loneliness and social isolation over time in older adults?

in the Republic of Ireland (Kearney, Cronin and O'Regan, 2011). In brief, the sampling frame used in TILDA was the Irish Geodirectory, a listing of residential addresses from which a clustered sample of addresses was chosen and stratified according to area, level of socioeconomic status, and geographical location. Addresses were selected within each geographic cluster, and all household residents $\geq 50$ years along with their spouses/partners were eligible to participate (Kearney et al., 2011). Data collection included a computer-assisted personal interview (CAPI); a self-completed questionnaire; and a health assessment. This study uses data from wave 1 (2009-11), wave 2 (201213), and wave 3 (2014-15). In total, the household response rate was $62 \%$ (8504 participants) for wave one, $86 \%$ (7455 participants) for wave two, and 62\% (6279 participants) for wave three. 
PHYSICAL ACTIVITY, LONELINESS \& SOCIAL ISOLATION

The data were provided free of charge through an online application process for the purposes of this analysis by the Irish Social Science Data Archive (ISSDA) at University College Dublin (http://www.ucd.ie/issda/data/tilda/) and the Interuniversity Consortium for Political and Social Research (ICPSR) at the University of Michigan (http://www.icpsr.umich.edu/icpsrweb/ICPSR/studies/34315). Ethical approval for TILDA was obtained from the Trinity College Dublin Research Ethics

\section{Assessment of Physical Activity (PA)}

PA was assessed using the International Physical Activity Questionnaire (IPAQ) (short form), a selfreported measure of time spent over the last 7 days on different PA levels (reliability: 0.89; validity: 0.80; Craig et al., 2003; Hallal et al., 2012). From the IPAQ we included the total minutes of vigorous physical activity (VPA) like heavy lifting, digging, aerobics, or fast bicycling; moderate physical activity (MPA) like carrying light loads, bicycling at a regular pace, or doubles tennis; and walking activity at work and home, travelling from place to place, and walking for recreation, sport, exercise, or leisure completed over a week (total mins per week).

\section{Assessment of loneliness, social isolation, and social asymmetry}

\section{Loneliness}

The Office for National Statistics (ONS) recommend the use of both direct and indirect measures to assess loneliness, and refer to the University of California-Los Angeles (UCLA) Loneliness scale (Russell, 1996) (UCLA) as a direct measure, and the single question 'How often do you feel lonely?' as a subjective measure (Snape \& Martin, ONS, 2018). Both measures are available from TILDA and are used in this analysis.

Previous research suggests that the (20 item long-form) has a high internal consistency (coefficient a ranging from 0.89 to 0.94$)$ and test-retest reliability over a 1-year period ( $r=0.73$ ) (Russell, 1996). A short form version of the UCLA (UCLA-6) was also found to have a good test-retest reliability $(r=0.66)$ (Xu et al., 2018). The direct measure included in this analysis is the modified version of the UCLA which 
PHYSICAL ACTIVITY, LONELINESS \& SOCIAL ISOLATION

154

155

156

157

assesses loneliness using five questions: How often do you feel left out?; How often do you feel isolated; How often do you feel in tune with the people around you?; How often do you feel you lack companionship?; and How often do you feel lonely? (often, some of the time, hardly ever). Higher scores indicate greater loneliness (score range 1-10).

The indirect measure employs item- 5 of the modified UCLA a self-reported question: How often do you feel lonely? (rarely or never, some of the time, moderate amount of the time, and all the time). Higher scores indicate greater loneliness (score range 1-4).

\section{Social isolation}

TILDA uses the size of participants' social network to measure social isolation using the Berkman-Syme Social Network Index (SNI) (Cohen et al., 1997). SNI is a composite measure of four types of social connection: marital status (married versus not); sociability (number and frequency of contact with children, close relatives, and close friends); church group membership; and membership in other community organisations. The SNI is a well-validated scale for measuring social networks and has been used to predict both short- and long-term mortality (Berkman \& Syme, 1979; House et al., 1982). This index is scored on a 0-4 composite scale and higher scores indicate less social isolation.

\section{Social asymmetry}

To address the discrepancy between desired and actual social networks where someone may feel lonely whilst having a large social network, or not feel lonely despite having a lack of social network (McHugh et al., 2017), the UCLA and SNI measures (as described above) have been combined in a measure of social asymmetry. Social asymmetry is introduced as an interaction within the model such that the outcome variable of PA is affected by an individual's score on social isolation, but that effect also depends on the individual's score on UCLA.

\section{Covariates}

Research suggests that socio-demographic covariates of age (years), sex (male/female), marital status (single, married, widowed, divorced), employment status (yes/no), and education (primary, 
PHYSICAL ACTIVITY, LONELINESS \& SOCIAL ISOLATION

secondary, higher) play an important role in loneliness (Schrempft et al., 2019; Shvedko et al., 2018). Additionally, general health status measured using a self-reported question (how is your health? excellent/very good/good/fair/poor), and cognitive health (orientation, comprehension, attention, recall, and language skills) measured using the Mini Mental State Exam (MMSE; Folstein et al., 1975) were also included in the analysis (Schrempft et al., 2019; Shvedko et al., 2018).

Evidence also highlights the beneficial impact of social participation on health and wellbeing in older adults ( $\geq 60$ years) and so the summed total of 15 questions relating to structured activities (e.g. attending classes, participating in sport activities or exercise, and undertaking voluntary activities were asked); unstructured activities (e.g. such as visiting people, reading a book, watching television, listening to music or the radio, going to see a play, eating out, working in the garden, carrying out hobbies, playing cards/games, and going to the pub; and a question on voting participation: yes/no) was included (Aartsen \& Jylhä. 2011; Levasseur et al., 2011, Maier \& Klumb, 2005).

\section{Statistical analysis}

Characteristics of the study population were summarised using descriptive statistics (Table 1).

A cross lagged path model was used to investigate the longitudinal associations between loneliness (UCLA, self-rated loneliness, and social isolation) and PA (IPAQ: walking, MPA, and VPA) over three waves of data (across six years) adjusted for prespecified covariates based on existing literature, (Alwin, 2007) (Figure 1). An interaction effect of social asymmetry was introduced into the model to explain PA.

Model fit was evaluated using a Root Mean Square Error of Approximation (RMSEA) $\leq 0.05$ with an upper limit $(90 \% \mathrm{Cl}) \leq 0.08$; a Comparative Fit Index (CFI) $\geq 0.95$; and a Standardised Root Mean Square Residual (SRMR) $\leq 0.08$ (Hoyle, 1995). Where the levels of fit indices were not achieved, the modification indices were examined, and where appropriate, adjustments were made. Statistical significance was set at $p<0.05$. A high estimate (Est) indicates a strong effect/relationship, whilst a low 
PHYSICAL ACTIVITY, LONELINESS \& SOCIAL ISOLATION

203

204

205

206

207

208

209

210

211

212

213

214

215

216

217

218

219

220

221

222

223

224

225

226

estimate indicates a weaker effect/relationship. All analyses were conducted in Mplus (version 7.4; Muthen \& Muthen, Los Angeles, CA).

Maximum likelihood estimation with robust standard errors (MLR) was used and is robust to nonnormality (Enders, 2013; Yaun \& Bentler, 2000). Missing data were assumed to be missing at random where systematic differences between the missing and observed values are assumed to be explained by other observed variables (Schafer \& Graham, 2002). MLR utilises a model-based strategy for dealing with missing data which enables all participants to be included in analysis.

\section{Results}

In brief, the sample analysed in this study consisted of 8,504 participants with a mean age of 63 $(S D=9.41)$ years. $56 \%$ were female; $70 \%$ were married; $70 \%$ had a secondary education or above; and 95\% experienced good-to-excellent health.

$81 \%$ of the sample reported that they rarely felt lonely, and mean scores for loneliness (UCLA: mean, SD: wave 1 1.92, 2.19; wave 2 1.92, 2.19; wave 3 1.69, 2.07), and social isolation (mean, SD: wave 1 $2.86,0.88$; wave $32.79,0.91$ ) indicated that the sample had low levels of loneliness and isolation. $52 \%$ of participants indicated that they did not participate in social activities. The model described the data well where fit statistics showed Root Mean Square Error of Approximation $\leq 0.05$ (RMSEA=0.04) (with an upper limit $\leq 0.08(90 \% \mathrm{Cl}=0.03,0.04)$; a Comparative Fit Index $\geq 0.95$ (CFI=0.98); and a Standardised Root Mean Square Residual $\leq 0.08$ (SRMR=0.03) (Hoyle, 1995).

The results from the path analysis are summarised in Table 2 and are described below.

\section{Direct effects}

\section{Physical activity (Wave 1, 2, and 3)}

Table 2 shows that PA (VPA, MPA, or walking) did not have any statistically significant effect on the measures of loneliness (UCLA, self-rated loneliness) or social isolation excluding an effect between 
PHYSICAL ACTIVITY, LONELINESS \& SOCIAL ISOLATION

walking at wave two and UCLA at wave $3(E s t=-0.05 ; \mathrm{SE}=0.02)$ where higher levels of walking reduced feelings of loneliness.

VPA at wave one had a statistically significant direct effect on VPA at wave two (Estimate (Est) $=0.05$; Standard error $(\mathrm{SE})=0.01)$, and VPA at wave two had a statistically significant direct effect on VPA at wave three $(\mathrm{Est}=0.12 ; \mathrm{SE}=0.02)$. MPA at wave one did not have a statistically significant direct effect on MPA at wave two (Est=0.02; $\mathrm{SE}=0.01$ ), but MPA at wave two had a statistically significant direct effect on MPA at wave three (Est=0.11; SE=0.02). Similarly, walking at wave one did not have a statistically significant direct effect on walking at wave two $(\mathrm{Est}=0.01 ; \mathrm{SE}=0.01)$, but walking at wave two had a statistically significant direct effect on walking at wave three (Est=0.10; $S E=0.02)$.

UCLA, self-rated loneliness, and social isolation (Wave 1, 2, and 3)

Table 2 shows that UCLA at wave one had a statistically significant direct effect on UCLA at wave two (Est=0.91; SE=0.04), and UCLA at wave two had a statistically significant direct effect on UCLA at wave three (Est $=0.91 ; \mathrm{SE}=0.02$ ). Self-reported loneliness at wave one had a statistically significant direct effect on self-reported loneliness at wave two ( $E s t=0.82 ; \mathrm{SE}=0.06)$, and self-reported loneliness at wave two had a statistically significant direct effect on self-reported loneliness at wave three (Est=0.81; $S E=0.05)$. Similarly, social isolation at wave one had a statistically significant direct effect on social isolation at wave three ( $E s t=0.86 ; \mathrm{SE}=0.02)$.

There were no statistically significant direct effects of the measures of UCLA or self-rated loneliness on any measure of PA (VPA, MPA, walking). However, social isolation at wave 1 had a statistically significant direct effect on VPA at wave two ( $\mathrm{Est}=0.05 ; \mathrm{SE}=0.02)$, and wave three $(\mathrm{Est}=0.07 ; \mathrm{SE}=0.03$ ); MPA at wave two (Est=0.05; $\mathrm{SE}=0.02)$; and walking at wave three $(\mathrm{Est}=0.07 ; \mathrm{SE}=0.03)$.

There were no statistically significant direct effects of social asymmetry on VPA, MPA or walking.

\section{Total effects (indirect and direct)}


PHYSICAL ACTIVITY, LONELINESS \& SOCIAL ISOLATION

Table 3 shows that there were no statistically significant total effects between the UCLA loneliness score, self-rated loneliness, or social asymmetry and VPA, MPA, or walking over time.

A statistically significant total effect between social isolation at wave one and VPA, MPA, and walking at wave three was shown suggesting that social isolation has a cumulative effect on PA level over time via its effect on social isolation and PA. For example, a statistically significant total relationship between social isolation at wave one and VPA at wave three $(E s t=0.12 ; S E=0.02)$ was shown via the indirect effect of VPA at wave two (Figure 1: path $\mathrm{G}+\mathrm{B}$ ), social isolation at wave 3

(Figure 1: path $\mathrm{C}+\mathrm{H}$ ), VPA at wave two and social isolation at wave three (Figure 1: path $\mathrm{G}+\mathrm{F}+\mathrm{I}$ ), $\mathrm{MPA}$ at wave two and social isolation at wave three (Figure 1: path $\mathrm{G}+\mathrm{F}+\mathrm{I}$ ), walking at wave two and social isolation at wave three (Figure 1: path $\mathrm{G}+\mathrm{F}+\mathrm{I}$ ), and the direct effect between social isolation at wave one and VPA at wave three (Figure 1: path J).

A statistically significant total effect between social isolation at wave one and MPA at wave three $(E s t=0.14 ; S E=0.02)$ was also shown via the indirect effect of MPA at wave two (Figure 1: path $G+B)$, social isolation at wave 3 (Figure 1: path $\mathrm{C}+\mathrm{H}$ ), VPA at wave two and social isolation at wave three (Figure 1: path $\mathrm{G}+\mathrm{F}+\mathrm{I}$ ), MPA at wave two and social isolation at wave three (Figure 1: path $\mathrm{G}+\mathrm{F}+\mathrm{I}$ ), walking at wave two and social isolation at wave three (Figure 1: path $\mathrm{G}+\mathrm{F}+\mathrm{I}$ ), and the direct effect between social isolation at wave one and MPA at wave three (Figure 1: path J).

Additionally, a statistically significant total relationship between social isolation at wave one and walking at wave three $(E s t=0.06$; Est=0.02) was shown via the indirect effect of walking at wave two (Figure 1: path $\mathrm{G}+\mathrm{B}$ ), social isolation at wave 3 (Figure 1: path $\mathrm{C}+\mathrm{H}$ ), VPA at wave two and social isolation at wave three (Figure 1: path $\mathrm{G}+\mathrm{F}+\mathrm{I}$ ), MPA at wave two and social isolation at wave three (Figure 1: path $\mathrm{G}+\mathrm{F}+\mathrm{I}$ ), walking at wave two and social isolation at wave three (Figure 1: path $\mathrm{G}+\mathrm{F}+\mathrm{I}$ ), and the direct effect between social isolation at wave one and walking at wave three (Figure 1: path J). 
PHYSICAL ACTIVITY, LONELINESS \& SOCIAL ISOLATION

The results also showed that age (VPA: Est=-0.01; $\mathrm{SE}=0.01$; MPA: Est=-0.08; $\mathrm{SE}=0.02$; walking: Est=0.07; $\mathrm{SE}=0.01$ ), sex (VPA: Est=-2.06; $\mathrm{SE}=0.20 ; \mathrm{MPA}: \mathrm{Est}=-1.52 ; \mathrm{SE}=0.25$; walking: Est=-0.44; $\mathrm{SE}=0.18$ ) and health status (VPA: Est=-0.63; $\mathrm{SE}=0.10 ; \mathrm{MPA}$ : $\mathrm{Est}=-0.58 ; \mathrm{SE}=0.12$; walking: $\mathrm{Est}=-0.63 ; \mathrm{SE}=0.09$ ) were statistically significant for all PA levels. Social participation was statistically significant for VPA $(E s t=0.57 ; S E=0.15)$ and MPA (Est=0.89; $S E=0.19)$ only. MMSE $(E s t=0.12 ; S E=0.05)$ and marital status (Est=0.18; $\mathrm{SE}=0.09$ ) were statistically significant for walking only.

Age (UCLA: Est=0.26; $\mathrm{SE}=0.05$; social isolation: $E s t=0.01 ; \mathrm{SE}=0.00$ ); sex (self-rated loneliness: Est=0.07; $S E=0.03$; social isolation: $E s t=0.10 ; S E=0.03$ ); marital status (UCLA: $E s t=0.26 ; S E=0.05$; selfrated loneliness: $\mathrm{Est}=0.07 ; \mathrm{SE}=0.01$; social isolation: $\mathrm{Est}=-0.36$; $\mathrm{SE}=0.02$ ); health status (UCLA: Est=0.36; $S E=0.04$; self-rated loneliness: $\mathrm{Est}=0.07 ; \mathrm{SE}=0.01$; social isolation: $\mathrm{Est}=0.36 ; \mathrm{SE}=0.04$ ); social participation levels (UCLA: Est=-0.18; $\mathrm{SE}=0.09$; social isolation: $\mathrm{Est}=0.58 ; \mathrm{SE}=0.03$ ); and MMSE score (UCLA: Est=-0.11; $\mathrm{SE}=0.03$; social isolation: $\mathrm{Est}=0.03 ; \mathrm{SE}=0.01$ ) were statistically significant for both loneliness and social isolation. Employment status (UCLA: Est $=0.13 ; \mathrm{SE}=0.06$ ) was statistically significant for loneliness only.

\section{Discussion}

This is one of a few studies to investigate the association between PA and loneliness over time using a large nationally representative sample of community-dwelling older adults. A path analysis was used to investigate the hypothesis that PA mediates loneliness, or loneliness mediates PA controlling for covariates of age; marital status; sex; physical and mental health; education; employment; and social participation. Fit statistics indicated that the model described the data well.

\section{Summary of findings}

Loneliness and social isolation are related but different concepts (McHugh et al., 2017; Perlman \& Peplau, 1981), and distinguishing between the two concepts is important because it allows more targeted interventions to be identified. For example, this analysis shows that higher levels of social isolation, not loneliness were directly associated with lower levels of walking over six years, MPA over three years and VPA over three and six years. Social isolation also had a total effect on walking, MPA, 
PHYSICAL ACTIVITY, LONELINESS \& SOCIAL ISOLATION

and VPA via its effect on PA and social isolation over six years. Additionally, higher levels of walking were associated with lower levels of loneliness based on a modified version of the UCLA scale over a 3-year period.

National PA guidelines encourage increased levels of PA for mental health benefits such as decreased depression and loneliness (Care DoHas, 2019), and the results from this study support this, with the finding that increased levels of walking may reduce feelings of loneliness in older community-dwelling adults, over a 3-year period. This finding is further supported by cross-sectional analyses (Shellito \& Roldan, 2019: $n=6,157$ participants; Yu et al., 2017: $n=181$ participants). Our study also found no association between MPA or VPA with the measures of loneliness or social isolation which is supported by a previous systematic review and meta-analysis of clinical trials exploring the effects of PA interventions on social isolation, loneliness and low social support in older adults (Schvedko et al., 2018: $n=38$ studies; 5288 participants; $51-82$ years), as well as a recent clinical trial exploring the effects of an exercise referral programme on PA and health of older adults (Tully et al., 2019: $n=1360$ participants; mean age 75 years). However, whilst walking is considered a safe and popular form of increasing PA (Arnardottir et al., 2013; Department of Health 2011; Franco et al., 2015) consensus as to which types of PA contribute to the classifications of light (LPA), MPA or VPA is lacking. Walking for example, can be classed as either low, moderate, or vigorous and so there may be an overlap across classifications within studies (Milton et al., 2018). Future research should seek to understand the type of PA to more fully understand the effects of different intensities of walking in relation to loneliness. Additionally, it is not possible to identify whether the walking activity was carried out in a group setting and therefore it is not possible to establish whether this finding supports loneliness reduction theories in the context of PA. Consequently, further studies exploring walking within individual or group setting should be explored.

The results from this study showed that social isolation predicted lower levels of VPA, and MPA over a 3-year period and over the longer term of six years: VPA, MPA and walking. Social Compensation 
PHYSICAL ACTIVITY, LONELINESS \& SOCIAL ISOLATION

effect model (Ferraro \& Farmer, 1998) highlights the importance of social support in the context of the effectiveness of PA intervention for reducing loneliness (Shvedko et al., 2018). Socially isolated individuals have diminished self-regulation, an individual's capacity to change emotions or behaviour to meet the social norms exerted by their social contacts, which leads to a decreased motivation to participate in PA (Cacioppo et al., 2000, 2014; Ekkekakis \& Petruzzello, 1999; Hawkley et al., 2007, 2009; McAuley et al., 2007; Labouvie-Vief \& Medler, 2002). Similarly, Schrempft et al.'s (2019) crosssectional study among 267 participants (mean 66.01 years) found that time spent in light ( $\beta=-0.143$, $p=0.015)$ and moderate to vigorous PA (MVPA) $(\beta=-0.112, p=0.051)$ was less frequent in more isolated participants; and Kobayashi and Steptoe's (2018) 10-year longitudinal study among 3,392 older adults ( $\geq 52$ years) found that socially isolated participants were less likely to report weekly MVPA $(R R=0.86$; 0.77-0.97). Further research is needed to explore specific strategies that may be effective in supporting socially isolated individuals to increase PA.

However, a previous longitudinal analysis among 229 participants (50-68 years) found that loneliness predicted diminished odds of PA $(O R=0.61)$, and greater likelihood of transitioning from PA to inactivity $(O R=1.58)$ over three years (Hawkley et al., 2009). This study found that loneliness based on UCLA score or self-rated loneliness is not significantly associated with PA level. The differences in results may be due to the characteristics of our sample where $81 \%$ rarely felt lonely and $95 \%$ were in good health which may have biased the findings.

\section{Strengths and limitations}

Previous studies have highlighted the dynamic nature of loneliness and social isolation experienced by older adults, and so understanding the association between PA and both loneliness and social isolation within a life course perspective is important to better inform the design of more effective interventions in a rapidly aging society (Victor et al., 2009; Wenger \& Burholt, 2004). Another key strength of this study is that it uses a quasi-simplex path analysis which simultaneously estimates both direct and indirect associations therefore enabling exploration of the reciprocal relationship between self-reported PA and measures of loneliness using longitudinal data over a 6-year period. Additionally, 
PHYSICAL ACTIVITY, LONELINESS \& SOCIAL ISOLATION

this analysis addresses the discrepancy between desired and actual social networks by combining the measures of loneliness (UCLA) and social isolation to form a measure of social asymmetry (McHugh et al., 2017) and introducing this as an interaction within the model such that the outcome variable of PA is affected by an individual's score on social isolation, but that effect also depends on the individual's score on UCLA. This study is one of the first studies to explore social asymmetry and PA, and whilst finding no association, further investigation is warranted.

In terms of limitations however, the TILDA dataset has not been specifically designed to address the research question of this current study, but provides repeated measures of the same individuals and so is an opportunity to explore the research question in a less expensive and time intensive way than would be possible using a study design that includes prospective data collection (Smith et al., 2011). Additionally, the model assumes factorial invariance of the measures (Hays et al., 1994; Selig \& Little, 2012), and as this study includes only observed measures, it is not possible to test the assumption of factorial invariance. Consequently, the findings should be considered with caution and future research should consider including multiple measures to create a latent construct to address measurement error (Selig \& Little, 2012). Additionally, the measures included in the analysis may give rise to bias. For example, the model includes repeated measures across time which may address factorial invariance but may give rise to a retest effect (Selig \& Little, 2012). The measures are also subjective and may be influenced by health status, mood, depression, anxiety, or cognitive ability, as well as seasonal variation, social desirability, (Dyrstad et al., 2014; Murphy, 2009; Saelens et al., 2012). Furthermore, inaccuracy of self-reported PA may be more exaggerated among older adults because of recall error (Dyrstad et al., 2014; Murphy, 2009; Saelens et al., 2012). However, despite these concerns, self-reported PA has shown to have convergent validity with objective measures of PA in older adults (87-89 years) (Innerd et al., 2015).

This study also assumes that all the important predictors are included in the analysis, but there are many determinants of human behaviour which may potentially confound the results (Selig \& Little, 
PHYSICAL ACTIVITY, LONELINESS \& SOCIAL ISOLATION

2012) and as with any observational study we cannot rule out the potential for residual confounding.

Future studies should, where possible, consider objective measures and additional predictors over time to address some of these biases (Bauman et al., 2009).

Another consideration is that previous research has been limited by difficulties in the recruitment of lonely older people (Dickens et al., 2011). This is evident from the characteristics of the sample included in this analysis where $81 \%$ of the sample rarely felt lonely, and mean scores for loneliness (UCLA: mean, SD: wave 1 1.93, 4.72; wave 2 1.92, 4.79; wave 3 1.69, 4.27), and social connectedness (mean, SD: wave $12.86,0.77$; wave $32.79,0.83$ ) indicated low levels of loneliness. Therefore, the sample characteristics may bias the findings.

Additionally, a limitation of this study is that the measure of PA used does not provide details of the context or type of PA carried out (e.g. individual versus group activities). Therefore, this study does not support loneliness reduction theories such as Social Compensation Effect theory (Ferraro \& Farmer, 1995, Sheridan et al., 2014), the Broaden and Build Theory of Positive Emotions (Cohen \& Wills, 1985; Fredrickson, 1998; Milligan et al., 2013; Newhall et. al., 2013, or the Tripartite Model of Group Identification (Hawkley et al., 2009; Henry et al., 1999). Future research should seek to include more detailed measures of PA that include the context in which the PA was carried out.

Despite the limitations of this study, to the authors' knowledge, it is one of only a few to assess the association between PA and loneliness, social isolation and social asymmetry in a nationally representative sample of community-dwelling adults across time.

\section{Conclusion}

A key message from this study is that social isolation, and not loneliness, is associated with lower levels of PA (VPA, MPA, and walking) over time. This finding supports the importance of social support provided through PA participation and proposes that lack of social networks reduces both selfregulatory and social control processes that in turn reduce healthy behaviours such as PA. Future research should seek to add to the understanding of loneliness and social isolation within the context 
PHYSICAL ACTIVITY, LONELINESS \& SOCIAL ISOLATION

402

403

404

405

406

407

408

409

410

411

412

413

414

415

416

417

418

419

420

421

422

of PA using an intervention study to explore a walking intervention for older adults and explore the effects of different setting (e.g. group versus individual) on loneliness and social isolation over time.

\section{References}

Aartsen, M., \& Jylhä, M. (2011). Onset of loneliness in older adults: Results of a 28-year prospective study. European Journal of Ageing, 8(1), 31-8.

AgeUK. (2018). Campaign to end loneliness.org. Retrieved on May 27, 2019, from: https://www.campaigntoendloneliness.org/loneliness-research/.

Alwin, D. F. (2007). The margins of error: a study of reliability in survey measurement. WileyBlackwell. Hoboken, New Jersey. Downloaded on 30th March, 2020 from: https://bok.cc/book/492656/e588de.

Arnardottir, N.Y., Koster, A., Van Domelen, D.R., et al. (2013). Objective measurements of daily physical activity patterns and sedentary behaviour in older adults: Age, Gene/Environment Susceptibility-Reykjavik Study, Age Ageing, 42, 222-29.

Bangsbo, J., Blackwell, J., Boraxbekk, C., et al. (2019). Copenhagen Consensus statement 2019: Physical activity and ageing. British Journal of Sports Medicine, Published Online First: 21 February 2019. Doi: 10.1136/bjsports-2018-100451.

Bauman, A., Ainsworth. B., Bull, F., et al. (2009). Progress and pitfalls in the use of the International Physical Activity Questionnaire (IPAQ) for adult physical activity surveillance. Journal of Physical Activity and Health, 6, S5-S8. PMID: 19998844.

Beaumont, J. (2012). Measuring national well-being - Older people and loneliness. Office of National Statistics. Downloaded on $6^{\text {th }}$ April 2020 from: https://webarchive.nationalarchives.gov.uk/20160106033529/http://www.ons.gov.uk/ons/r 
PHYSICAL ACTIVITY, LONELINESS \& SOCIAL ISOLATION

el/wellbeing/measuring-national-well-being/older-people-and-loneliness/art-measuringnational-well-being--older-people-and-loneliness.html

Berkman, L. F., \& Syme, S. (1979). Social networks, host resistance, and mortality: A nine-year followup study of Alameda County residents. American Journal of Epidemiology, 109(2), 186-204.

Bernard, S. (2013). Loneliness and social isolation among older people in North Yorkshire, working paper (WP2565). Social Policy Research Unit, University of York 2013. Retrieved on April 30, 2019 from https://www.york.ac.uk/inst/spru/research/pdf/lonely.pdf.

Bukov, A., Maas, I., \& Lampert, T. (2002). Social participation in very old age: Cross-sectional and longitudinal findings from BASE. Berlin Aging Study. Journal of Gerontology Series B Psychological Sciences and Social Science, 57, 510-17.

Care DoHaS. (2019). UK Chief Medical Officers' Physical Activity Guidelines. London: Department of Health and Social Care; 2019.

Dickens, A.P., Richards, S.H., Hawton, A., et al. (2011). An evaluation of the effectiveness of a community mentoring service for socially isolated older people: A controlled trial. BMC Public Health, 11, 218. Doi: 10.1186/1471-2458-11-218.

Cacioppo, J.T., \& Cacioppo, S. (2014). Social relationships and health: the toxic effects of perceived social isolation. Social and Personality Psychology Compass, 58-72. Retrieved on May 27, 2019 from https://doi.org/10.1111/spc3.12087.

Cacioppo, J.T., Ernst, J.M., Burleson, M.H., et al. (2000). Lonely traits and concomitant physiological processes: The MacArthur social neuroscience studies. International Journal of Psychophysiology, 35, 143-54.

Cohen, S., Doyle, W. J., Skoner, D. P., et al. (1997). Social ties and susceptibility to the common cold. Journal of the American Medical Association, 277 (24), 1940-44. Doi:10.1001/jama.1997.03540480040036. 
PHYSICAL ACTIVITY, LONELINESS \& SOCIAL ISOLATION

449 Cohen, S., \& Wills, T.A. (1985). Stress, social support, and the buffering hypothesis. Psychological Bulletin, 98, 310-57. Retrieved on April 30, 2019 from https://psycnet.apa.org/record/1986-

Craig, C.L., Marshall, A.L., Sjöström, M., et al. (2003). International Physical Activity Questionnaire: 12-country reliability and validity. Medicine and Science in Sports and Exercise, 1381-95.

Cunningham, C., O' Sullivan, R., Caserotti, P., \& Tully, M.A. (2020). Consequences of physical inactivity in older adults: A systematic review of reviews and meta-analyses. Scandinavian Journal of Medicine \& Science in Sports, 30(5), 816-27. Doi: 10.1111/sms.13616.

Department of Health (DOH). (2011). UK physical activity guidelines. Retrieved on September 5, 2019 from: http://www.dh.gov.uk/en/Publicationsandstatistics/Publications/PublicationsPolicyAndGuid ance/DH 127931

Desrosiers, J., Noreau, L., \& Rochette, A. (2004). Social participation of older adults in Quebec. Aging Clinical and Experimental Research, 16, 406-12.

Dickens, A.P., Richards, S.H., Greaves, C.J., \& Campbell, J.L. (2011). Interventions targeting social isolation in older people: a systematic review. BMC Public Health, 11, 647. Doi: http://www.biomedcentral.com/1471-2458/11/647.

Dyrstad, S.M., Hansen, D.M., Holme, I.M., \& Anderssen, S.A. (2014). Comparison of self-reported versus accelerometer-measured physical activity. Medicine \& Science in Sports \& Exercise,

Ekkekakis, P., \& Petruzzello, S.J. (1999). Acute aerobic exercise and affect: Current status, problems, and prospects regarding dose-response. Sports Medicine, 28, 337-74. 
PHYSICAL ACTIVITY, LONELINESS \& SOCIAL ISOLATION

Elovainio, M., Hakulinen, C., Pulkki-Råback, L., et al. (2017). Contribution of risk factors to excess mortality in isolated and lonely individuals: an analysis of data from the UK biobank cohort study. Lancet Public Health,2, e260-66. Doi: 10.1016/S2468-2667(17)30075-0.

Enders, C.K. (2013). Dealing with missing data in developmental research. Child Development Perspectives, 7, 27-31.

Ferraro, K.F., \& Farmer, M.M. (1995). Social compensation in adulthood and later life. Compensating for psychological deficits and declines: Managing losses and promoting gain. Chapter 6, 12745. Retrieved on April 30, 2019 from https://books.google.co.uk/books?hl=en\&|r=\&id=P8rIWdFqTuUC\&oi=fnd\&pg=PA127\&dq=Fe rraro+KF,+Farmer+MM.+Social+compensation+in+adulthood+and+later+life.+Compensating +for+Psychological+Deficits+and+Declines:+Managing+Losses+and+Promoting+Gain.+1995:1 27\%E2\%80\%9345.\&ots=YyEoQ50C$\underline{P \& s i g=G e y P J w q s F 2 P Q x x z J p J 510 S C f N N E \& \text { redir esc }=y \# v=o n e p a g e \& q \& f=f a l s e}$

Folstein, M.F., Folstein, S.E., \& McHugh, P.R. (1975). "Mini-mental state". A practical method for grading the cognitive state of patients for the clinician. Journal of Psychiatric Research, 12(3), 189-98.

Franco, M.R., Tong, A., Howard, K., et al. (2015). Older people's perspectives on participation in physical activity: a systematic review and thematic synthesis of qualitative literature. British Journal of Sports Medicine, 1-9. Doi: 10.1136/bjsports-2014-094015.

Fredrickson, B. L. (1998). What good are positive emotions? Review of General Psychology, 2, 30019. Doi:10.1037/1089-2680.2.3.300.

Fried, L., Prohaska, T., Burholt, V., et al. (2020). A unified approach to loneliness. Lancet, 395 (10218), 114. Doi:10.1016/S0140-6736(19)32533-4. 
PHYSICAL ACTIVITY, LONELINESS \& SOCIAL ISOLATION

494

495

496

497

498

499

500

501

502

503

504

505

506

507

508

509

510

511

512

513

514

Glass, T.A., De Leon, C.F.M., Bassuk, S.S., \& Berkman, L.F. (2006). Social engagement and depressive symptoms in late life: longitudinal findings. Journal of Aging and Health, 18, 604-28.

Griffin, J. (2010). The lonely society? London: Mental Health Foundation.

Hallal, P.C., Andersen, L.B., Bull, F., et al. (2012). Global physical activity levels: surveillance, progress, pitfalls, and prospects. The Lancet, 380, 247-57.

Hawkley, L.C., Thisted, R.A., \& Cacioppo, J.T. (2009). Loneliness predicts reduced physical activity: Cross-sectional \& longitudinal analyses. Health Psychology, 28(3), 354-63. Doi:10.1037/a0014400.

Hawkley, L.C., \& Cacioppo, J.T. (2007). Aging and loneliness: Downhill quickly? Current Directions in Psychological Science, 16, 187-91.

Hays, R.D., Marshall, G.N., Wang, E.Y.I., et al., (1994). Four-year cross-lagged associations between physical and mental health in the medical outcomes study. Journal of Consulting and Clinical Psychology, 62(3), 441-49.

Henry, K.B., Arrow, H., \& Carini, B. (1999). A tripartite model of group identification theory and measurement. Small Group Research, 30, 558-81. Retrieved on April 30, 2019 from https://doi.org/10.1177/104649649903000504

House, J., Robbin, C., \& Metzner, H. (1982). The association of social relationships and activities with mortality: Prospective evidence from the Tecumseh community health study. American Journal of Epidemiology, 116(1), 123-40.

Hoyle, R.H. (1995). Structural Equation Modelling: Concepts, issues and applications. Thousand Oaks, CA: Sage Publications, 1-132. 
PHYSICAL ACTIVITY, LONELINESS \& SOCIAL ISOLATION

Innerd, P., Catt, M., Collerton, et al. (2015). A comparison of subjective and objective measures of physical activity from the Newcastle 85+ study. Age and Ageing, 44(4), 691-94. https://doi.org/10.1093/ageing/afv062

Kearney, P.M., Cronin, H., \& O’Regan, C. (2011). Cohort profile: The Irish longitudinal study of ageing. International Journal of Epidemiology, 40, 877-84.

Kobayashi L.C., \& Steptoe, A. (2018). Social isolation, loneliness, and health behaviors at older ages: longitudinal cohort study. Annals of Behavioral Medicine, 52, 582-93.

Labouvie-Vief, G., \& Medler, M. (2002). Affect optimization and affect complexity: Modes and styles of regulation in adulthood. Psychology and Aging, 17, 571-88.

Lauder, W., Mummery, K., Jones, M., \& Caperchione, C. (2006). A comparison of health behaviours in lonely and non-lonely populations. Psychology Health \& Medicine, 11(2), 233-45.

Levasseur, M., Gauvin, L., Richard, L., et al. (2011). Associations between perceived proximity to neighborhood resources, disability, and social participation among community-dwelling older adults: Results from the VoisiNuAge study. Archives of Physical Medicine and Rehabilitation, 92(12), 1979-86.

Maier, H., \& Klumb, P.L. (2005). Social participation and survival at older ages: is the effect driven by activity content or context? European Journal of Ageing, 2(1), 31-9.

Milligan, C., Dowrick, C., Payne, S., et al. (2013). Men's sheds and other gendered interventions for older men: improving health and wellbeing through social activity-A systematic review and scoping of the evidence base. Lancaster University Centre for Ageing Research: Lancaster.

Milton, K., Vareia, A.R., Strain, T., et al. (2018). A review of global surveillance on the muscle strengthening and balance elements of physical activity recommendations. Journal of Frailty Sarcopenia and Falls, 3 (2), 114-124. Doi: 10.22540/JFSF-03-114. 
PHYSICAL ACTIVITY, LONELINESS \& SOCIAL ISOLATION

Murphy, S.L. (2009). Review of physical activity measurement using accelerometers in older adults: considerations for research design and conduct. Preventive Medicine, 48, 108-14.

McAuley, E., Morris, K.S., Motl, R.W., Hu, L., Konopack, J.F., \& Elavsky, S. (2007). Long-term follow-up of physical activity behavior in older adults. Health Psychology, 26, 375-80.

McHugh, J.E., Kenny, R.A., Lawlor, B.A., Steptoe, A., \& Kee, F. (2017). The discrepancy between social isolation and loneliness as a clinically meaningful metric: Findings from the Irish and English longitudinal studies of ageing (TILDA and ELSA). International Journal of Geriatrics and Psychiatry, 32(6), 664-74.

Newall, N.E., Chipperfield, J.G., Bailis, D.S., et al. (2013). Consequences of loneliness on physical activity and mortality in older adults and the power of positive emotions. Health Psychology, 32, 921. Downloaded on April 30, 2019 from: https://doi.org/10.1037/a0029413.

Nicholson, N.R. (2012). A review of social isolation: An important but underassessed condition in older adults. The Journal of Primary Prevention, 33(2-3), 137-52.

Patterson, A.C., \& Veenstra, G. (2010). Loneliness and risk of mortality: a longitudinal investigation in Alameda County, California. Social Science \& Medicine, 71(1), 181-86.

Pels, F., \& Kleinert, J. (2016). Loneliness and physical activity: A systematic review. International Review of Sport and Exercise Psychology, 9(1), 231-60. Doi: 10.1080/1750984x.2016.1177849.

Perlman, D., \& Peplau, L.A. (1981). Toward a social psychology of loneliness. In: Duck, S.W., Gilmour, R., editors. Personal relationships in disorder. London: Academic Press; 1981. p. 31-56.

Pitkala, K.H., Routasalo, P., Kautiainen, H., Sintonen, H., \& Tilvis, R.S. (2011). Effects of socially stimulating group intervention on lonely, older people's cognition: a randomized, controlled trial. American Journal of Geriatric Psychiatry, 19(7), 654-63. 
PHYSICAL ACTIVITY, LONELINESS \& SOCIAL ISOLATION

561

562

563

564

565

566

567

568

569

570

571

572

573

574

575

576

577

578

579

580

581

582

583

Russell, D. (1996). UCLA Loneliness Scale (Version 3): Reliability, validity, and factor structure. Journal of Personality Assessment, 66, 20-40.

Saelens, B.E., Sallis, J.F., Frank, L.D., et al. (2012). Neighborhood environmental and psychosocial correlates of adults' physical activity. Medical Science of Sports Exercise, 44, 637-46.

Schafer, J.L., \& Graham, J.W. (2002). Missing data: our view of the state of the art. Psychological Methods, 7(2), 147-77.

Schrempft, S., Jackowska, M., Hamer, M., \& Steptoe, A. (2019). Associations between social isolation, Ioneliness, and objective physical activity in older men and women. BMC Public Health, 19(74). Doi: https://dspace.lboro.ac.uk/2134/36669.

Schvedko, A.V., Thompson, J.L., Greig, C.A., \& Whittaker, A.C. (2018). Physical activity interventions for treatment of social isolation, loneliness or low social support in older adults: A systematic review and meta-analysis of randomised controlled trials. Psychology of Sports Exercise, 34, 128-37.

Selig, J.P., \& Little, T.D. (2012). Autoregressive and cross-lagged panel analysis for longitudinal data. Handbook of Develomental Research Methods. Chapter 16, Autoregressive and cross-lagged panel analysis for longitudinal data, Editors: B. Laursen, T. D. Little, N. A. Card, 265-78.

Senez, B., Felicioli, P., Moreau, A., \& Le Goaziou, M.F. (2004). Quality of life assessment of type 2 diabetic patients in general medicine. Presse Medicale, 33(3), 161-66.

Shankar, A., McMunn, A., Banks, J., \& Steptoe, A. (2011). Loneliness, social isolation, and behavioral and biological health indicators in older adults. Health Psychology, 30 (4), 377-85.

Shellito N., \& Roldan, N.V. (2019). Walking away from loneliness: The mediating role of social isolation. Innovation in Aging, 3(1). S836-S837. Doi: https://doi.org/10.1093/geroni/igz038.3082. 
PHYSICAL ACTIVITY, LONELINESS \& SOCIAL ISOLATION

584

585

586

587

588

589

590

591

592

593

594

595

596

597

598

599

600

601

602

603

604

605

606

607

Sheridan, D., Coffee, P., \& Lavallee, D. (2014). A systematic review of social support in youth sport. International Review of Sport and Exercise Psychology, 7(1), 198-228. Doi:10.1080/1750984X.2014. 931999

Silverman, M. N., \& Deuster, P. A. (2014). Biological mechanisms underlying the role of physical fitness in health and resilience. Interface focus, 4(5), 20140040. Doi:10.1098/rsfs.2014.0040.

Smith, A.K., Ayanian, J.Z., Covinsky, K.E., et al. (2011). Conducting high value secondary dataset analysis: an introductory guide and resources. Journal of General International Medicine, 26(8), 920-29.

Snape D., \& Martin, G. Office of National Statistics. (2018). Measuring loneliness: guidance for use of the national indicators on surveys. Downloaded on 30th January 2020 from: https://www.ons.gov.uk/peoplepopulationandcommunity/wellbeing/methodologies/measu $\underline{\text { ringlonelinessguidanceforuseofthenationalindicatorsonsurveys }}$

Solmi, M., Veronese, N., Galvano, D., et al. (2020). Factors associated with loneliness: An umbrella review of observational studies. Journal of Affective Disorders (2020), Doi: https://doi.org/10.1016/i.jad.2020.03.075

Steptoe, A., Shankar, A., Demakakos, P., \& Wardle, J. (2013). Social isolation, loneliness, and allcause mortality in older men and women. Proceedings of the National Academy of Sciences, 110 (15), 5797-801. Doi: 10.1073/pnas.1219686110. Downloaded on April 19, 2018 from www.pnas.org/cgi/doi/10.1073/pnas.1219686110.

Thurston, R.C., \& Kubzansky, L.D. (2009). Women, loneliness, and incident coronary heart disease. Psychosomatic Medicine, 71(8), 836-42.

Tully, M.A., McMullan, I.I., Blackburn, N.E., et al. (2019). Is sedentary behavior or physical activity associated with loneliness in older adults? Results of the European-wide SITLESS study. Journal of Aging and Physical Activity. 19, 1-7. Doi: 10.1123/japa.2019-0311. 
PHYSICAL ACTIVITY, LONELINESS \& SOCIAL ISOLATION

608

Umberson. D. (1987). Family status and health behaviours: Social control as a dimension of social integration. Journal of Health and Social Behaviour, 28, 306-19.

Victor, C. R., Scambler, S., Shah, S., et al. (2002). Has loneliness amongst older people increased? An investigation into variations between cohorts. Ageing \& Society, 22(1), 1-13.

Victor, C. R., Bond, J., \& Scambler, S. (2009). The social world of older people, Maidenhead: Open University Press.

Victor, C. (2011). Loneliness in old age: the UK perspective. Safeguarding the Convoy: a call to action from the campaign to end loneliness. Age UK Oxfordshire. Downloaded on April 30, 2019 from https://www.campaigntoendloneliness.org/wp-content/uploads/Safeguarding-theConvoy.-A-call-to-action-from-the-Campaign-to-End-Loneliness.pdf.

Walseth, K. (2006). Sport and belonging. International Review for the Sociology of Sport, 41(3-4), 447-64. Doi:10.1177/1012690207079510.

Weiss, R. (1975). Loneliness: The Experience of Emotional and Social Isolation. Cambridge, MA: The MIT Press.

Wenger, G.C., \& Burholt, V. (2004). Changes in levels of social isolation and loneliness among older people in a rural area: a twenty-year longitudinal study. Canadian Journal of Aging/la revue canadienne du vieillissement. 23, 115-27.

Xu, S., Qiu, D., Hahne, J., Zhao, M., \& Hu, M. (2018). Psychometric properties of the short-form UCLA Loneliness Scale (ULS-8) among Chinese adolescents. Medicine, 97(38), e12373.

\section{https://doi.org/10.1097/MD.0000000000012373}

Yu, R., Cheung, O., Lau, K., \& Woo, J. (2017). Associations between perceived neighborhood walkability and walking time, wellbeing, and loneliness in community-dwelling older Chinese people in Hong Kong. International Journal of Environmental Research and Public Health, 14, 1199. Doi:10.3390/ijerph14101199. 
PHYSICAL ACTIVITY, LONELINESS \& SOCIAL ISOLATION

632 Yuan, K.H., \& Bentler, P.M. (2000). Three likelihood-based methods for mean and covariance structure analysis with non-normal missing data. Sociological Methodology, 165-200. 